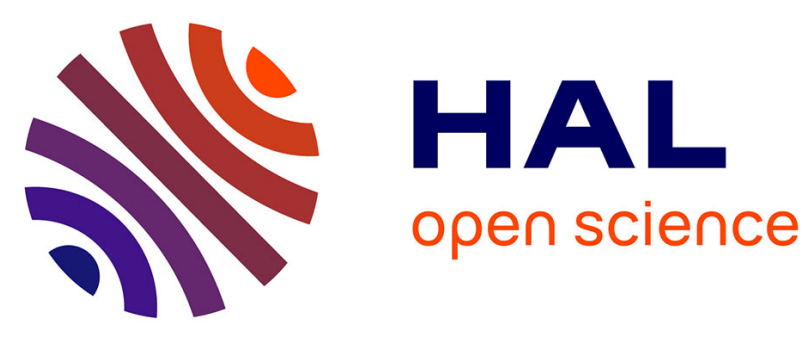

\title{
Synthesis of Branched-Chain Sugars with a DHAP-Dependent Aldolase: Ketones are Electrophile Substrates of Rhamnulose-1- phosphate Aldolases
}

Victor Laurent, Ekaterina Darii, Angelina Aujon, Marine Debacker, Jean-Louis Petit, Virgil Hélaine, Tibor Liptaj, Martin Breza, Aline Mariage, Lionel Nauton, et al.

\section{To cite this version:}

Victor Laurent, Ekaterina Darii, Angelina Aujon, Marine Debacker, Jean-Louis Petit, et al.. Synthesis of Branched-Chain Sugars with a DHAP-Dependent Aldolase: Ketones are Electrophile Substrates of Rhamnulose-1- phosphate Aldolases. Angewandte Chemie International Edition, 2018, 57 (19), pp.5467 - 5471. 10.1002/anie.201712851 . hal-02323732

\section{HAL Id: hal-02323732 \\ https://hal.science/hal-02323732}

Submitted on 22 Oct 2019

HAL is a multi-disciplinary open access archive for the deposit and dissemination of scientific research documents, whether they are published or not. The documents may come from teaching and research institutions in France or abroad, or from public or private research centers.
L'archive ouverte pluridisciplinaire HAL, est destinée au dépôt et à la diffusion de documents scientifiques de niveau recherche, publiés ou non, émanant des établissements d'enseignement et de recherche français ou étrangers, des laboratoires publics ou privés. 


\title{
Synthesis of branched-chain sugars with a DHAP-aldolase: ketones are electrophile substrates of rhamnulose-1-phosphate aldolases
}

\begin{abstract}
Dihydroxyacetone phosphate (DHAP)-dependent rhamnulose aldolases display an unprecedented versatility for ketones as electrophile substrates. We selected and characterized a rhamnulose aldolase from Bacteroides thetaiotaomicron (RhuABthet) to provide a proof of concept. DHAP was added as a nucleophile to several $\alpha$-hydroxylated ketones used as electrophiles. This aldol addition was stereoselective and produced branchedchain monosaccharide adducts with a tertiary alcohol moiety. Several aldols were thus readily obtained in good to excellent yields (from 76 to $95 \%$ ). These results contradict the general view that aldehydes are the only electrophile substrates for DHAP-aldolases and extend the chemists' toolbox to a new $\mathrm{C}-\mathrm{C}$ bond-forming enzyme for stereoselective synthesis of tertiary alcohols.
\end{abstract}

Victor Laurent, ${ }^{[\mathrm{a}]}$ Ekaterina Darii, ${ }^{[\mathrm{b}]}$ Angelina Aujon, ${ }^{[\mathrm{a}]}$ Marine Debacker, ${ }^{[\mathrm{a}]}$ Jean-Louis Petit,${ }^{[\mathrm{b}]}$ Virgil Hélaine, ${ }^{[a]}$ Tibor Liptaj, ${ }^{[c]}$ Martin Breza, ${ }^{[c]}$ Aline Mariage, ${ }^{[b]}$ Lionel Nauton, ${ }^{[a]}$ Mounir Traïkia, ${ }^{[a]}$ Marcel Salanoubat, ${ }^{[b]} \dagger$, Marielle Lemaire ${ }^{[a]} \dagger$, Christine Guérard-Hélaine, ${ }^{*[a]} \dagger$ and Véronique de Berardinis ${ }^{*[b]} \dagger$

Branched-chain monosaccharides belong to a class of rare sugars ${ }^{[1]}$ that usually contain a tertiary alcohol moiety. They are generally found as constituents of more complex natural compounds, including molecules with chemotherapeutic properties, such as antibiotics. ${ }^{[2]}$ Dendroketose, a non-natural representative of this class of sugars, can be obtained by selfaldolization of dihydroxyacetone (DHA), ${ }^{[3]}$ and can be dehydrated to 4-hydroxymethylfurfural. ${ }^{[3 b], ~[4]}$ Furfural derivatives, such as 4- or 5-hydroxymethylfurfural, are important building blocks for a large variety of compounds and are often cited in the literature as molecular platforms for the production of polymers and fine chemicals. ${ }^{[5]}$ They can also be used to prepare certain biofuels. ${ }^{[3 b],[6]}$

The asymmetric synthesis of tertiary alcohol moieties in general, as well as in the context of branched-chain sugars and their analogs, is highly challenging in organic chemistry. Although tertiary alcohols can be easily obtained by the addition of an organometallic reagent to a ketone, these reactions rarely provide high asymmetric induction, particularly when broadening

[a] V. Laurent, A. Aujon, M. Debacker, L. Nauton, Dr M. Traïkia, Dr C. Guérard-Hélaine, Dr V. Hélaine, Prof M. Lemaire Université Clermont Auvergne, CNRS, SIGMA Clermont, Institut de Chimie de Clermont-Ferrand, F-63000 Clermont-Ferrand E-mail: christine.helaine@uca.fr

[b] Dr E. Darii, A. Mariage, J.-L. Petit, Dr V. de Berardinis, Dr M. Salanoubat

Génomique Métabolique, Genoscope, Institut François Jacob, CEA, CNRS, Univ Evry, Univ Paris-Saclay, 91057 Evry, France E-mail: vberard@genoscope.cns.fr

[c] Dr T. Liptaj, M. Breza

Slovak University of Technology, Faculty of Chemical and Food Technology, Radlinského 9, 81237 Bratislava, Slovakia E-mail: tibor.liptaj@stuba.sk

$+\quad$ These authors contributed equally to this work

Supporting information for this article is given via a link at the end of the document the set of substrates and/or products. Most require stoichiometric amounts of chiral ligands. In addition, the conventional chemical synthesis of these valuable building blocks is still hampered by the use of harmful reagents, such as heavy metal catalysts. More sustainable methods have been recently developed to circumvent these disadvantages. However, enantio-enriched tertiary alcohols were obtained with only moderate stereocontrol ${ }^{[7]}$. Alternative solutions, such as enzymatic transformations, have been explored using, for example, hydrolases ${ }^{[8]}$. Enzyme catalyzed carboligation methods are less common and, in this context, aldolases can favorably complement well-established thiamine diphosphate-dependent enzymes and hydroxynitrile lyases. ${ }^{[8]}$ To date, only pyruvate aldolases (PyrAl) are used to provide a tertiary alcohol moiety, but their poor substrate scope has limited their use in preparative applications. ${ }^{[9]}$ The use of aldolases to promote enzymatic $\mathrm{C}-\mathrm{C}$ bond formation to give rise to tertiary alcohols is yet underexplored.

Here, we showed that some rhamnulose-1-phosphate aldolases (RhuAs) can catalyze cross-aldolization between dihydroxyacetone phosphate (DHAP) as nucleophile and DHA as electrophile, enabling the synthesis of a branched-chain sugar called dendroketose-1-phosphate. We also examined the structural diversity of the electrophile ketones that enable the aldolization reaction. This paves the way for the synthesis of valuable chiral synthons containing a tertiary alcohol moiety.

In a previous study, we identified new DHA aldolases that catalyze aldolization between DHA and glyceraldehyde-3phosphate $(D, L-G 3 P)^{[10]}$ by directly monitoring the formation of hexose-6-phosphate (Scheme 1A) in cell lysates. One of the hits (C2JUR4 from Lactobacillus rhamnosus), annotated as RhuA attracted our attention because: (1) RhuAs are known to exclusively use DHAP as a nucleophile, ${ }^{[11]}$ although, in some cases, RhuAs are also able to convert DHA when complexed with borate or arsenate ${ }^{[12]}$ (not present in our screening conditions), and (2) G3P is not known to be an electrophilic substrate for RhuAs. Based on these two points, we hypothesized that the expected hexose-6-phosphate was unlikely to be the product of the reaction. Thus, C2JUR4 was overexpressed in E. coli and purified. First, we demonstrated the formation of rhamnulose-1-phosphate from DHAP and Llactaldehyde, confirming that C2JUR4 is a RhuA. Second, the product of a small-scale reaction using DHA and D,L-G3P was analyzed by NMR, revealing that it was actually dendroketose-1phosphate (1), which could result from the addition of DHAP as the nucleophile to DHA as the electrophile (Scheme 1B). This assumption is supported by the presence of an endogenous $E$. coli triose phosphate isomerase (TPI) in the cell lysate and purified enzyme, which isomerizes D-G3P into DHAP (Scheme 1). We still detected TPI activity in enzyme samples after IMAC 
purification.

electrophile

Scheme 1. (A) previous screening for DHA aldolase activity. (B) Dendroketose-1-phosphate formation through an enzyme-catalyzed aldo reaction.

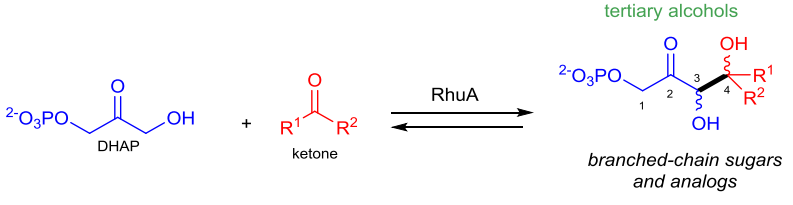

Scheme 2. RhuA-catalyzed tertiary alcohol formation.

We further investigated whether this unexpected reaction is common within the RhuA family. We used a sequence-driven approach $^{[13]}$ to build a small library representative of the functional diversity of the RhuA family using experimentally confirmed RhuA ${ }^{[14],[15]}$ and C2JUR4 from Lactobacillus rhamnosus as references. We selected a total of 21 proteins, all annotated RhuA, with a high degree of amino-acid sequence diversity (Table S1). Their corresponding genes were cloned (Table S2) and the proteins overexpressed. We tested the reaction for dendroketose-1-phosphate formation for the 21 selected enzymes using DHAP and DHA as nucleophile and electrophile substrates, respectively. The $\mathrm{m} / \mathrm{z}$ value of the detected product was identical to that of dendroketose-1. phosphate.

We selected RhuA from Bacteroides thetaiotaomicron (RhuA $A_{\text {thet }}$; Uniprot Id: Q8A1A0) as a proof of concept to evaluate the biocatalytic abilities of these proteins to produce branched-chain sugars by adding DHAP to various ketones (scheme 2).

We first optimized the reaction conditions of this class II aldolase. $\mathrm{Co}^{2+}$ and $\mathrm{Mn}^{2+}$ were found to be the best cations (see $\mathrm{SI}) . \mathrm{Co}^{2+}$ was used for subsequent studies. In 1996, Hixon et al. ${ }^{[17]}$ demonstrated that RhuA $A_{E \text { coli }}$ was able to use $\mathrm{O}_{2}$ as an electrophile substrate, resulting in the oxidation of DHAP to give hydroxypyruvaldehyde phosphate (HPP). In addition, DHAP is known to be unstable, yielding chemical degradation products. ${ }^{[18]}$ Considering these results, we examined the behaviour of RhuA $_{B \text { thet }}$ in the sole presence of DHAP. Spectrophotometric assays using $\mathrm{NADH}$ with glycerophosphate dehydrogenase (GPDH) as the coupled enzyme confirmed the oxidation of DHAP into the aldehyde HPP. In addition, HPP was itself a substrate of GPDH, but at a slower rate than DHAP. All following reactions were thus performed under an argon atmosphere using oxygen-free solutions (see SI) to prevent unwanted DHAP consumption. To reach a complete conversion of DHAP and to avoid tedious purification steps, a large excess of electrophile was employed. ${ }^{[19]}$ Finally, to prevent any decomposition of the phosphorylated adducts, known as fragile products, ${ }^{[20]}$ we set up the reaction time around 5 hours. Thus, the reactions required large amounts of enzyme but the quantities remained acceptable $(0.25 \mathrm{~mol} \%)$ regarding the ease of its purification (His-tagged biocatalyst) along with the good level of its overexpression (see SI). Under these conditionsthe reaction for dendroketose-1-phosphate formation was scaled up, the product purified and the structure of compound 1 was unambiguously confirmed (see SI). Moreover bona fide dendroketose ${ }^{[3 \mathrm{~b}]}$ was produced from compound $\mathbf{1}$ after hydrolysis with acidic phosphatase.

Second, we investigated the catalytic potential of RhuA $A_{B \text { thet }}$ to produce tertiary alcohols from various electrophiles using 13 commercially available ketones. They were chosen to cover a wide range of structural diversity. Reactions were monitored, both by following the disappearance of DHAP and aldol adduct formation by mass spectrometry (Table 1). Aldolization reactions between DHAP and several activated ketones, i.e. those bearing an electron withdrawing group ( $\alpha$-hydroxy or another carbonyl), were successful with good conversion (75 to 100\%). On the contrary, we observed no conversion with non-activated ketones, i.e. acetone, butanone, cyclopentanone, or 4-hydroxybutan-2one, under our experimental conditions.

We selected four ketones (hydroxyacetone, 1hydroxybutanone, hydroxypyruvate and L-erythrulose) for further investigation based on the following criteria: i) commercial availability in an optically pure form, ii) DHAP conversion above $85 \%$, and iii) a propensity of the aldol to cyclize, enabling easy assignment of the configuration of the newly created asymmetric centers. Aldol adducts were then synthesized at a hundred milligram scale and fully characterized. All expected compounds (Table 2) were obtained with good to excellent yields (76 to $95 \%)$.

We used data from the literature, molecular modelling, and NMR analysis to determine the stereochemistry of the two newly created stereocenters (C3 and C4) for all except for compound 1 (Table 2), for which $\mathrm{C} 4$ is not an asymmetric center.

RhuA $_{E c o l i}$ has been crystallized ${ }^{[21]}$ and found to be strictly $3 R$ stereoselective due to mechanistic requirements. ${ }^{[21 b, c], ~[22] ~}$ Indeed, the reactive nucleophilic DHAP cis-enediolate that is formed can only offer its re face to the electrophile, the si face being non-accessible. On the contrary, the configuration of C4 can vary, due to weaker anchoring of the electrophile within the active site, offering either its re or si face to the nucleophile.

We constructed a RhuA $A_{B t h e t}$ model by sequence-homology modeling using the RhuA $A_{E c o l i} 3 D$ structure (PDB id: 1GT7) and Modeler9v18 software. ${ }^{[23]}$ The tetrameric form of $\mathrm{RhuA}_{B \text { thet }}$ was rebuilt by docking DHAP in the active site model to replace the phosphoglycolohydroxamic acid found in 1GT7 and Nanoscale Molecular Dynamics (NAMD) ${ }^{[24]}$ experiments were conducted. The nucleophilic cis-enediolate-DHAP appeared to present only its re face to the electrophile, thus resulting in a strict $3 R$ configuration (see $\mathrm{SI}$ ) like $\mathrm{RhuA}_{E \text { colli. }}$ This is consistent with the sole formation of rhamnulose-1-phosphate when reacting DHAP and L-lactaldehyde.

We determined the $\mathrm{C} 4$ configuration as illustrated in Scheme 3 . The ${ }^{13} \mathrm{C}$ NMR spectrum of $\mathbf{2}$ showed the presence of two compounds. Dephosphorylation of $\mathbf{2}$ using an acidic 
Table 1. Screening of ketones as electrophiles with RhuA $A_{B t h e t}$.

$$
{ }^{2-} \mathrm{O}_{3} \mathrm{PO}{ }_{\mathrm{pH}} \mathrm{R}_{7.5, \mathrm{Co}^{2+}, \mathrm{RT}, \mathrm{Ar}}^{\mathrm{R}^{1} \text { and } \mathrm{R}^{2} \neq \mathrm{H}}
$$

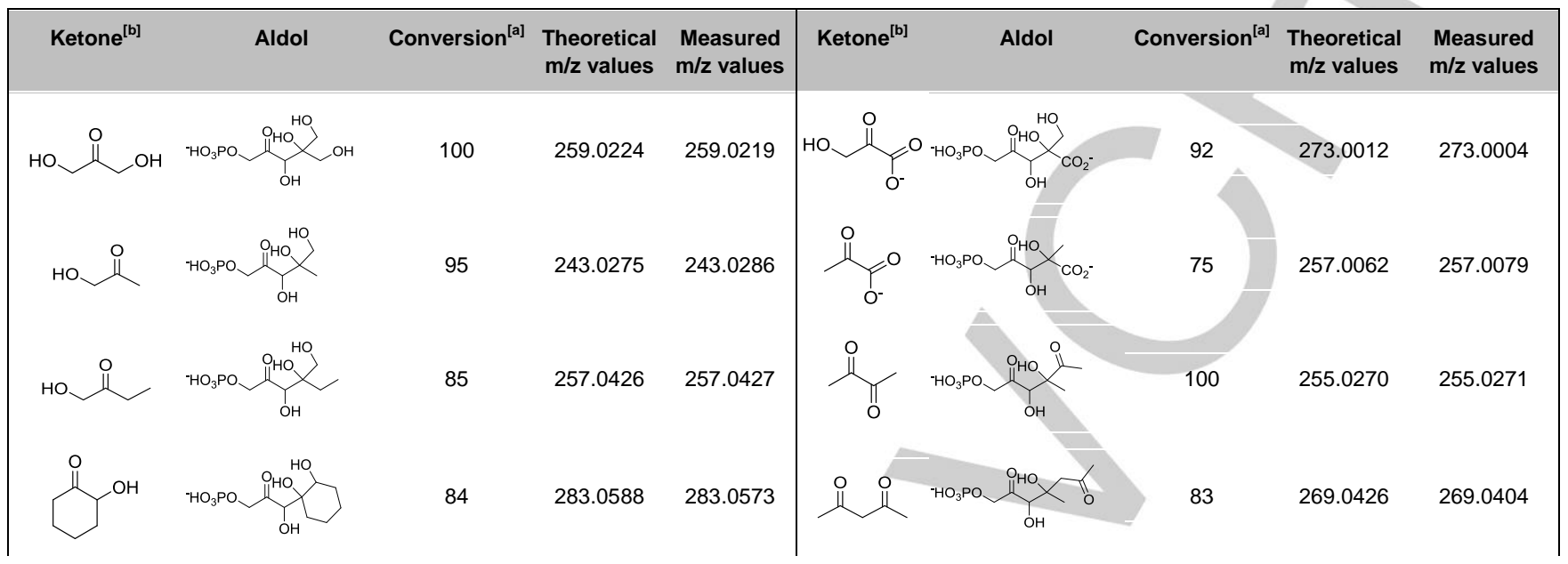

phosphatase gave a mixture of two epimers (65/35), unambiguously characterized by comparison with published data, ${ }^{[25]}$ as major $(3 R, 4 R)$ and minor $(3 R, 4 S)$ diastereoisomers. 


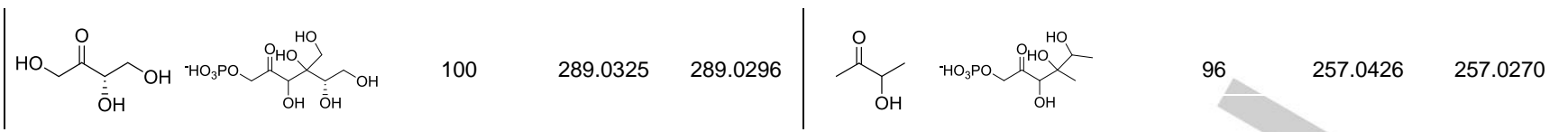
[a] DHAP consumption in \%; reaction conditions: $1 \mathrm{mg}$ aldolase, $8 \mu \mathrm{mol} \mathrm{DHAP}, 8 \mu \mathrm{L} \mathrm{CoCl} 2(10 \mathrm{mM}), 10$ eq. ketone and water to reach $200 \mu \mathrm{L}$ final volume, pH 7.5, 5-h reaction time under Ar atmosphere. [b] Acetone, butanone, cyclopentanone, and 4-hydroxybutan-2-one gave no conversion under these conditions.

Table 2. Synthesis and characterization of five aldols

yield
configuration de $(\%)^{[\mathrm{b}]}$

[a] The aldols are drawn in their linear forms for simplicity. [b] de = diastereomer excess determined by ${ }^{1} \mathrm{H}$ NMR; reaction conditions: $30 \mathrm{mg}$ $\mathrm{RhuA}_{B_{\text {the }}, 0.4 \mathrm{mmol} \mathrm{DHAP}, 400 \mu \mathrm{L} \mathrm{CoCl}}(10 \mathrm{mM}), 5 \mathrm{eq}$. (dihydroxyacetone, hydroxypyruvate or L-erythrulose) or 15 eq. (hydroxyacetone or 1hydroxybutanone) electrophile in $12 \mathrm{~mL}$ water under $\mathrm{Ar}$ at $\mathrm{pH} 7.5$ and RT.

Compound 3 revealed a strong NOESY correlation between $\mathrm{H}_{3}$ and $\mathrm{H}_{5}$, as well as significant correlations with other protons of the ethyl group (see $\mathrm{SI}$ ), showing an $R$ configuration for C4 (see SI). Aldol $\mathbf{3}$ was present as a single stereoisomer, as depicted by its ${ }^{13} \mathrm{C}$ NMR spectrum, demonstrating that the aldolase was highly $4 R$ stereoselective when 1 hydroxybutanone was the electrophile.

Product $\mathbf{4}$ was obtained as a unique diastereoisomer, the configuration determined using molecular geometry calculations and additional NOE measurements. The calculations predict that the $\mathrm{CH}_{2} \mathrm{OPO}_{3}{ }^{2-}$ group is preferably in the cis- configuration to the $\mathrm{H}_{3}$ proton (isomer $A$, see $\mathrm{SI}$ ) when the isomer has a $(3 R, 4 R)$ configuration. Observed quantitative NOEs unambiguously confirmed such a cis- configuration and thus also confirmed the $(3 R, 4 R)$ configuration of 4 .

Finally, we obtained three forms of compound $\mathbf{5}$, as depicted by its ${ }^{13} \mathrm{C}$ NMR spectrum. Enzymatic dephosphorylation followed by acidic treatment showed formation of a single ketal isomer (see SI) with a $4 R$ configuration, as depicted by a correlation between $\mathrm{H}_{5}$ and $\mathrm{H}_{7}$. This result again illustrates the high stereoselectivity of the aldolase when converting Lerythrulose. These results all show that $R_{h u A_{B t h e t}}$ is highly stereoselective when the ketones bear large or charged substituents.

In conclusion, this work provides new access to the highly challenging tertiary alcohol moiety. Some activated ketones are now established as electrophile substrates for various rhamnulose-1-phosphate aldolases, highlighting unexpected substrate promiscuity. We demonstrated that RhuA from Bacteroides thetaiotaomicron stereoselectively catalyzed aldolization, producing optically pure tertiary alcohols. It should be noted that the conditions used for product characterization could be far from those used for synthesis purposes. Further developments are needed to reduce the amount of enzyme involved in the synthesis reaction as well as to optimize the ratio between ketones and DHAP. Furthermore, RhuA $A_{\text {Bthet }}$ can be used as a good starting point to achieve a more efficient biocatalyst for synthesis applications by protein engineering, Further studies are in progress to explore whether such substrate promiscuity is shared among the three other DHAPdependent aldolase families.

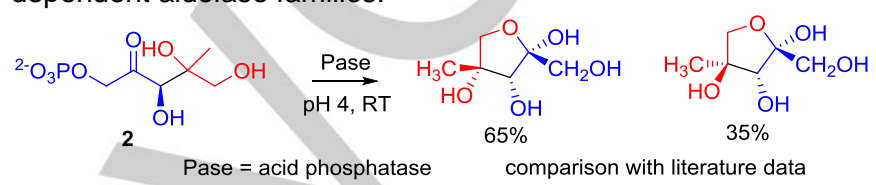

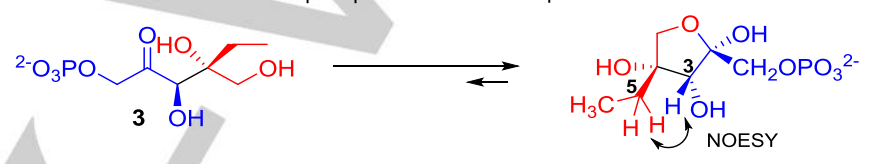

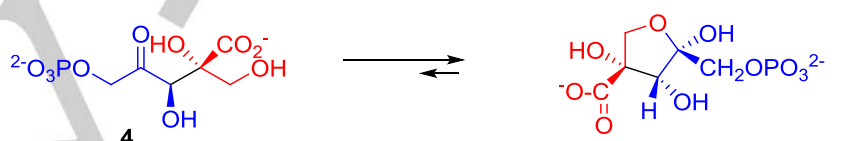

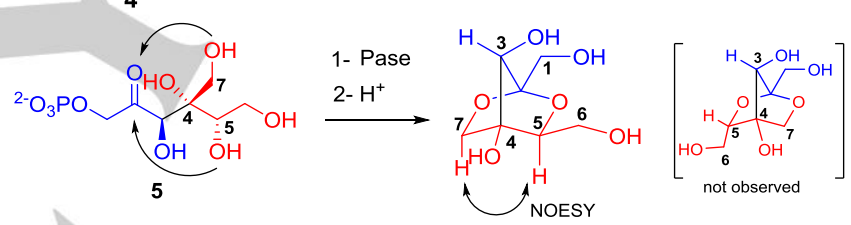

Scheme 3. Determination of the $\mathrm{C} 4$ absolute configuration for aldols 2-5.

\section{Acknowledgements}

We are grateful to Adrien Debard and Virginie Pellouin for excellent technical assistance. This work was supported by the Agence Nationale de la Recherche (ANR), Genozyme program (ANR-08-GENM-026). We thank Jean Weissenbach for helpful discussion on the project and improving the manuscript. T.L. acknowledges support of the Slovak funding agency VEGA - project 1/0770/15.

Keywords: tertiary alcohol $\cdot$ rhamnulose aldolase $\cdot$ carboligation - branched-chain sugar $\cdot$ promiscuous substrate

[1] a) Y. Chapleur, F. Chrétien, In Preparative Carbohydrate Chemistry (Ed.: S. Hanessian), Marcel Dekker: New York, 1997; pp 207-262. b) J. Yoshimura, Adv. Carbohydr. Chem. Biochem. 1984, 42, 69-134. c) W. D. Celmer, Pure Appl. Chem. 1971, 28, 413-453. d) S. Hanessian, Total Synthesis of Natural Products: The Chiron Approach; Pergamon: Oxford, 1983. e) B. Fraser-Reid, Acc. Chem. Res. 1996, 29, 57-66. f) M. Bamba, T. Nishikawa, M. Isobe, Tetrahedron 1998, 54, 6639-6650. g) N. Chida, J. Takeoka, K. Ando, N. Tsutsumi, S. Ogawa, Tetrahedron 1997, 53, 16287-16298. h) M. Sasaki, M. Inoue, K. Tachibana, J. Org. Chem. 1994, 59, 715-717. i) R. A. Alonso, C. S. Burgey, B. V. Rao, G D. Vite, R. Vollerthun, M. A. Zottola, B. Fraser-Reid, J. Am. Chem. Soc. 1993, 115, 6666-6672. J) A. Rauter, M. Ferreira, C. Borges, T. Duarte, F. Piedade, M. Silva, H. Santos, Carbohydr. Res. 2000, 325, 1-15. 
[2] a) T. Pathak, R. Bhattacharya, Carbohydr. Res. 2008, 343, 1980-1998. b) I. Das, T. K. Pal, C. G. Suresh, T. Pathak, J. Org. Chem. 2007, 72, 5523-5533. c) N. A. Jones, S. A. Nepogodiev, C. J. MacDonald, D. L. Hughes, R. A. Field, J. Org. Chem. 2005, 70, 8556-8559. d) Y Chapleur, F. Chretien, Prep. Carbohydr. Chem. 1997, 207-262. e) H. Miyano, Y. Sakai, T. Takeshita, Y. Ito, J. Kinjo, T. Nohara, Chem. Pharm. Bull. 1996, 44, 1228-1231.

[3] a) L. M. Utkin, Dokl. Akad. Nauk SSSR 1950, 67, 301-304. b) J. Deng, T. Pan, Q. Xu, M.-Y. Chen, Y. Zhang, Q.-X. Guo, Y. Fu, Sci. Rep., 2013, 3, 1244-1250.

[4] T. Wang, M. W. Nolte, B. H. Shanks, Green Chem. 2014, 16, 548-572.

[5] R.-J. van Putten, J. C. van der Waal, E. de Jong, C. B. Rasrendra, H. J. Heeres, J. G. de Vries, Chem. Rev. 2013, 113, 1499-1597.

[6] a) P. K. Rout, A. D. Nannawari, O. Prakash, A. Kalra, R. Rajaseklaran, Chem. Eng. Sci. 2016, 142, 318-346.

[7] a) J. Rong, T. pellegrini, S. R. Harutyunyau, Chem. Eur. J. 2016, 22 3558-3570. b) H. Wang, X.-J. Dai, C.-J. Li, Nat. Chem. 2017, 9, 374 378.

[8] a) R. Kourist, P. D. de Maria, U. T. Bornscheuer, ChemBioChem 2008, 9, 491-498. b) R. Kourist, U. T. Bornscheuer, Appl. Microbiol. Biotechnol. 2011, 91, 505-517. c) M. Müller, ChemBioEng Rev. 2014, 1 14-26. d) M. Richter, Enzymatic Asymmetric Synthesis of Tertiary Alcohols. Asymmetric Synthesis II: More Methods and Applications (Eds.: M. Christmann, S. Bräse), Wiley-VCH, 2012, pp 377-381. e) P. Lehwald, M. Richter, C. Röhr, H.-W. Liu, M. Müller, Angew. Chem., Int Ed. 2010, 49, 2389-2392.

[9] P. Clapés, X. Garrabou, Adv. Synth. Catal 2011, 13, 2263-2283.

[10] C. Guérard-Hélaine, V. De Berardinis, M. Besnard-Gonnet, E. Darii, M. Debacker, A. Debard, C. Fernandes, V. Hélaine, A. Matiage, V. Pellouin, A. Perret, J.-L. Petit, M. Sancelme, M. Lemaire, M. Salanoubat, ChemCatChem 2015, 7, 1871-1879

[11] W.-D Fessner, A. Schneider, H. Held, G. Sinerius, C. Walter, M. Hixon, J. V. Schloss, Angew. Chem., Int. Ed. Engl. 1996, 35, 2219-2221.

[12] a) M. Sugiyama, Z. Hong, L. J. Whalen, W. A. Greenberg, C.-H. Wong, Adv. Synth. Catal. 2006, 348, 2555-2559. b) X. Garrabou, J. Calveras J. Joglar, T. Parella, J. Bujons, P. Clapés, Org. Biomol. Chem 2011, 9 , 8430-8436.

[13] C. Vergne-Vaxelaire, F. Bordier, A. Fossey, M. Besnard-Gonnet, A Debard, A. Mariage, V. Pellouin, A. Perret, J. Petit, M. Stam, M. Salanoubat, J. Weissenbach, V. de Berardinis, A. Zaparucha, Adv. Synth. Catal. 2013, 355, 1763-1779.

[14] J. Badía, L. Baldoma, J. Aguilar, A. Boronat, FEMS Microbiology Letters, 1989, 65, 253-257.

[15] Z. Li, X. Wu, L. Cai, S. Duan, J. Liu, P. Yuang, H. Nakanishi, X.-D. Gao, Bioorg. Med. Chem. Lett., 2015, 25, 3980-3983.

[16] I. Oroz-Guinea, K. Hernandez, F. Camps-Bres, C. Guérard-Hélaine, M. Lemaire, P. Clapés, E. Garcia-Junceda, Adv. Synth. Catal. 2015, 357, 1951-1960.

[17] M. Hixon, G. Sinerius, A. Schneider, C. Walter, W.-D. Fessner, J. V. Schloss, FEBS Lett. 1996, 392, 281-284.

[18] T. Suau, G. Alvaro, M. D. Benaiges, J. Lopez-Santin, Biotechnol. Bioeng. 2006, 93, 48-55.

[19] I. Sánchez-Moreno, V. Hélaine, N. Poupard, F. Charmantray, B. Légeret, L. Hecquet, E. García-Junceda, R. Wohlgemuth, C. GuérardHélaine, M. Lemaire, Adv. Synth. Catal. 2012, 354, 1725-1730.

[20] R. Wohlgemuth, A. Liese, W. Streit, Trends Biotechnol. 2017, 35, 452 465.

[21] a) T.-H. Chiu, D. S. Feingold, biochemistry. 1969, 8, 98-108. b) W.-D. Fessner, G. Sinerius, A. Schneider, M. Dreyer, G. E. Schulz, J. Badia, J. Aguilar; Angew. Chem. Int. Ed. Engl. 1991, 5, 555-558. c) M. Kroemer I. Merkel, G. E. Schulz, Biochemistry 2003, 42, 10560-10568. d). D. Grueninger, G. E. Schulz, Biochemistry 2008, 47, 607-614

[22] L. Espelt, T. Parella, J. Bujons, C. Solans, J. Joglar, A. Delgado, P. Clapés, Chem. Eur. J. 2003, 9, 4887-4899.

[23] A. Šali, T. L. Blundell, J. Mol. Biol. 1993, 234, 779-815.
[24] J. C. Phillips, R. Braun, W. Wang, J. Gumbart, E. Tajkhorshid, E. Villa C. Chipot, R. D. Skeel, L. Kale, K. Schulten. J. Comput. Chem. 2005, 26, 1781-1802.

[25] D. Rao, A. Yoshihara, P. Gullapalli, K. Morimoto, G. Takata, F. P. da Cruz, S. F. Jenkinson, M. R. Wormald, R. A. Dwek, G. W. J. Fleet, K. Izumori, Tetrahedron Lett. 2008, 49, 3316-3321.

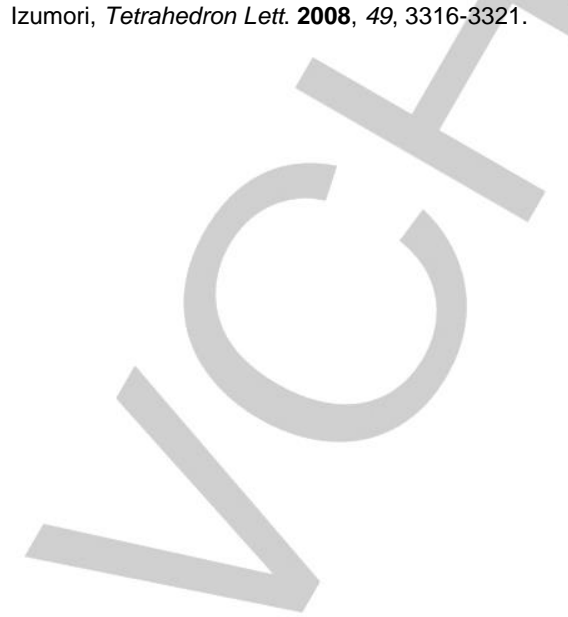




\section{COMMUNICATION}

Dihydroxyacetone phosphate (DHAP)-dependent rhamnulose aldolases have shown an unexpected tolerance for ketones as electrophile substrates, giving rise to branched-chain monosaccharides with a tertiary alcohol moiety in good yields. These results contradict the accepted view that the aldehydes are the unique electrophile substrates of DHAP-aldolases.

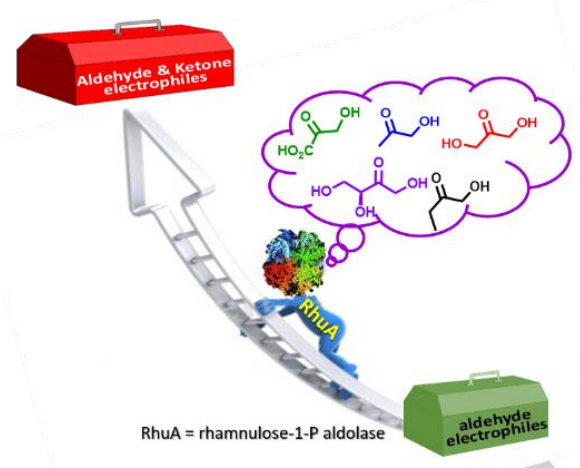

V. Laurent, E. Darii A. Aujon, M. Debacker, J.-L. Petit, V. Hélaine, T. Liptaj, M. Breza, A. Mariage, L. Nauton, M. Traïkia, M. Salanoubat, $M$. Lemaire, C. Guérard-Hélaine and V. de Berardinis

Page No. - Page No.

Synthesis of branched-chain sugars with a DHAP-aldolase: ketones are electrophile substrates of rhamnulose-1phosphate aldolases 